\title{
Effect of alkali metal doping on the properties and crystalline perfection of bis(thiourea)zinc(II) chloride crystals
}

\author{
K. Muthu - G. Bhagavannarayana • \\ S. P. Meenakashisundaram - S. C. Mojumdar
}

CTAS2011 Conference Special Chapter

(C) Akadémiai Kiadó, Budapest, Hungary 2012

\begin{abstract}
The influence of sodium doping on the properties of bis(thiourea)zinc(II) chloride crystals has been described. The reduction in the intensity observed in powder X-ray diffraction of doped specimen and slight shifts in vibrational frequencies confirm the lattice stress as a result of doping. The incorporation of $\mathrm{Na}(\mathrm{I})$ into the crystal lattice was confirmed by energy dispersive X-ray spectroscopy. Surface morphological changes due to doping of the alkali metal are observed by scanning electron microscopy. The TG-DTA studies reveal the purity of the material and no decomposition is observed up to the melting point. The high resolution X-ray diffraction studies reveal that the crystalline quality is improved considerably by doping with alkali metal. High transmittance is observed and cut off $\lambda$ is $\sim 270 \mathrm{~nm}$.
\end{abstract}

Keywords BTZC - Thiourea - XRD - SEM - HRXRD . Thermal analysis

K. Muthu $\cdot$ S. P. Meenakashisundaram

Department of Chemistry, Annamalai University,

Annamalainagar 608 002, Tamilnadu, India

G. Bhagavannarayana

Materials Characterization Division, National Physical

Laboratory, New Delhi 110 012, India

S. C. Mojumdar $(\bowtie)$

Department of Chemistry, University of Guelph, Guelph, ON, Canada

e-mail: scmojumdar@yahoo.com

S. C. Mojumdar

Department of Chemical Technologies and Enviroment, Faculty of Industrial Technologies, Trencin University of Alexander Dubceck, Puchov, Slovakia

\section{Introduction}

Bis(thiourea)zinc(II) chloride (BTZC) is a semi-organic nonlinear optical (NLO) material which finds applications in the area of laser technology, optical communication, data storage technology and optical computing because it has high resistance to laser induced damage, low angular sensitivity and good mechanical hardness compared to many organic NLO crystals [1-4]. Metal ion doped materials are currently receiving a great deal of attention due to the rapid development of laser diodes [5, 6]. Several foreign metallic cations existing in the parent compounds with high valency and small radii will affect the whole growth process and enhances physical properties. Their effects are related with ionic radius, electric charge, and frequency of solvent exchange [7-9].

The effect of doping on BTZC crystals has been studied elaborately in the past few years [10-13]. Influence of $\mathrm{pH}$ on the growth and characterization of BTZC crystal has been reported [14-18]. BTZC crystals were grown by Sankaranarayanan-Ramasamy method and characterized [19, 20]. Thermal, microscopic, X-ray and spectral analyses are very useful methods for materials characterization. Therefore, many authors have applied these techniques for various materials characterization [21-41]. In the present investigation, we have studied the effect of $\mathrm{Na}(\mathrm{I})$ on the lattice constant, XRD profile, crystallite size, vibratonal patterns, EDS, morphology and thermal properties of the BTZC crystal.

\section{Experimental}

Synthesis and crystal growth

BTZC was synthesized using AR grade zinc chloride and thiourea in a stoichimetric ratio 1:2. 


$$
\mathrm{ZnCl}_{2}+2 \mathrm{SC}\left(\mathrm{NH}_{2}\right)_{2} \rightarrow \mathrm{Zn}\left(\mathrm{SC}\left(\mathrm{NH}_{2}\right)_{2}\right)_{2} \mathrm{Cl}_{2}
$$

The purity of the synthesized (BTZC) materials was increased by successive recrystallization processes. Crystals were grown by slow evaporation solution growth technique. Doping of sodium (1 and $10 \mathrm{~mol} \%$ ) in the form of sodium chloride was performed during the crystallization process. The crystallization is took place within 15-20 days and the crystals were harvested when they attained an optimal size and shape.

\section{Measurements}

Powder XRD analysis was performed on a Philips Xpert Pro Triple-axis X-ray diffractometer at room temperature using a wavelength of $1.540 \AA$ with a step size of $0.008^{\circ}$. The XRD data is analyzed by Rietveld method with RIETAN-2000. Single-crystal X-ray diffraction was performed using an ENRAF- NONIUS CAD 4 instrument. A multicrystal XRD developed at NPL [42] has been used to record high-resolution diffraction curves (DCs). The FT-IR spectra were recorded for all the samples including pure BTZC using an AVATAR 330 FT-IR instrument using the $\mathrm{KBr}$ pellet technique in the range $500-4,000 \mathrm{~cm}^{-1}$. UVVis spectra were recorded using CARY 5E UV-Vis spectrophotometer. The surface morphology was observed on a JEOL JSM 5610 LV scanning electron microscope. In the $\mathrm{SEM}$, the image is formed and presented by a very fine electron beam, which is focused on the surface of the specimen. At any given moment, the specimen is bombarded with electrons over a very small area. Simultaneous TG-DTA curves were recorded on a SDT Q600 (TA instrument) thermal analyzer. The TG-DTA curves were simultaneously obtained in nitrogen at a heating rate of $10{ }^{\circ} \mathrm{C} \min ^{-1}$.

\section{Results and discussion}

The growth rate of crystal is high with low concentration of dopants while decreased with an increase in dopant concentration. Quite likely, at high concentrations of the dopant, the adsorption film blocks the growth surface and inhibits the growth process [43, 44]. Photographs of as-grown pure and doped crystals are shown in Fig. 1.

\section{FT-IR analysis}

A close observation of FT-IR spectra of pure BTZC and doped specimens reveal that doping generally results in small shifts in some of the characteristic vibrational frequencies (Fig. 2). It could be due to lattice strain developed as a result of doping. The $\mathrm{CN}$ stretching frequencies of
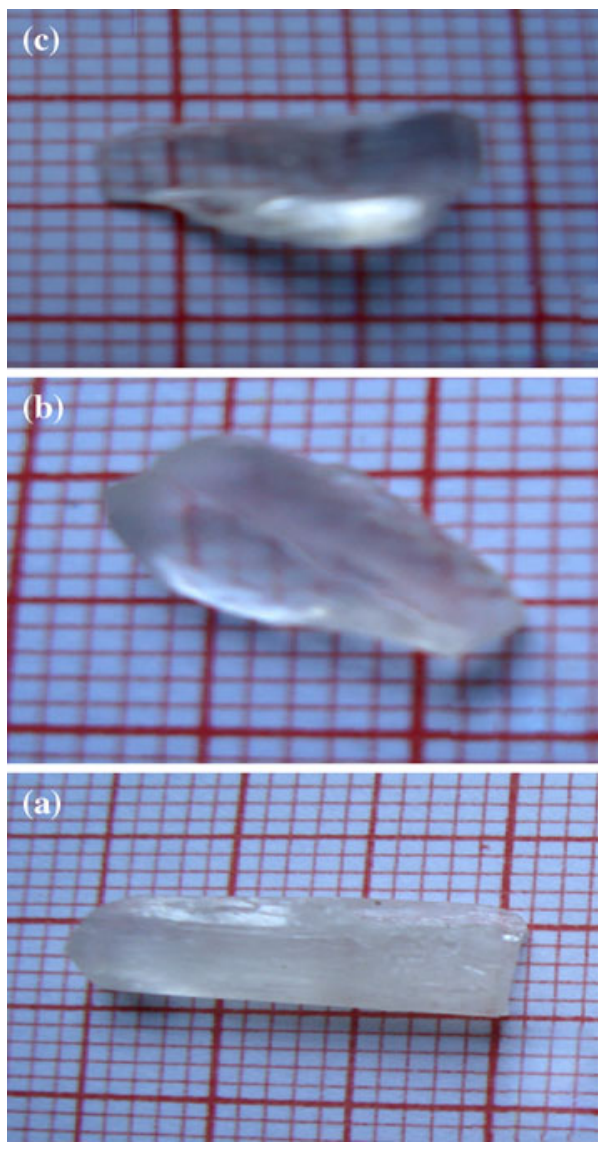

Fig. 1 Photographs of as-grown BTZC crystals a pure b $1 \mathrm{~mol} \%$ Na-doped and c $10 \mathrm{~mol} \%$ Na-doped

thiourea $\left(1,089\right.$ and $\left.1,472 \mathrm{~cm}^{-1}\right)$ are shifted to higher frequencies for pure and $\mathrm{Na}^{+}$-doped BTZC crystals $(\sim 1,102$ and $\left.\sim 1,495 \mathrm{~cm}^{-1}\right)$. The CS stretching frequencies $(1,417$ and $\left.740 \mathrm{~cm}^{-1}\right)$ are shifted to lower frequencies $(\sim 1,410$ and $\sim 715 \mathrm{~cm}^{-1}$ ) for pure and doped samples. These observations suggest that zinc coordinates with thiourea through sulfur atom.

\section{$X R D$ analysis}

The powder XRD patterns of $\mathrm{Na}(\mathrm{I})$-doped samples are compared with that of undoped one (Fig. 3). No new peaks or phases were observed by doping with alkali metal sodium. However, a drastic reduction in intensity is observed as a result of doping. The most prominent peaks with maximum intensity of the XRD patterns of pure and doped specimens are quite different. The observations could be attributed to strain in the lattice. The cell parameters are determined from the single crystal X-ray diffraction analysis and the values of the lattice constants of pure and doped BTZC crystals are given in the Table 1. The ionic radius of the dopant $\mathrm{Na}$ (I) (102 pm) is high when 


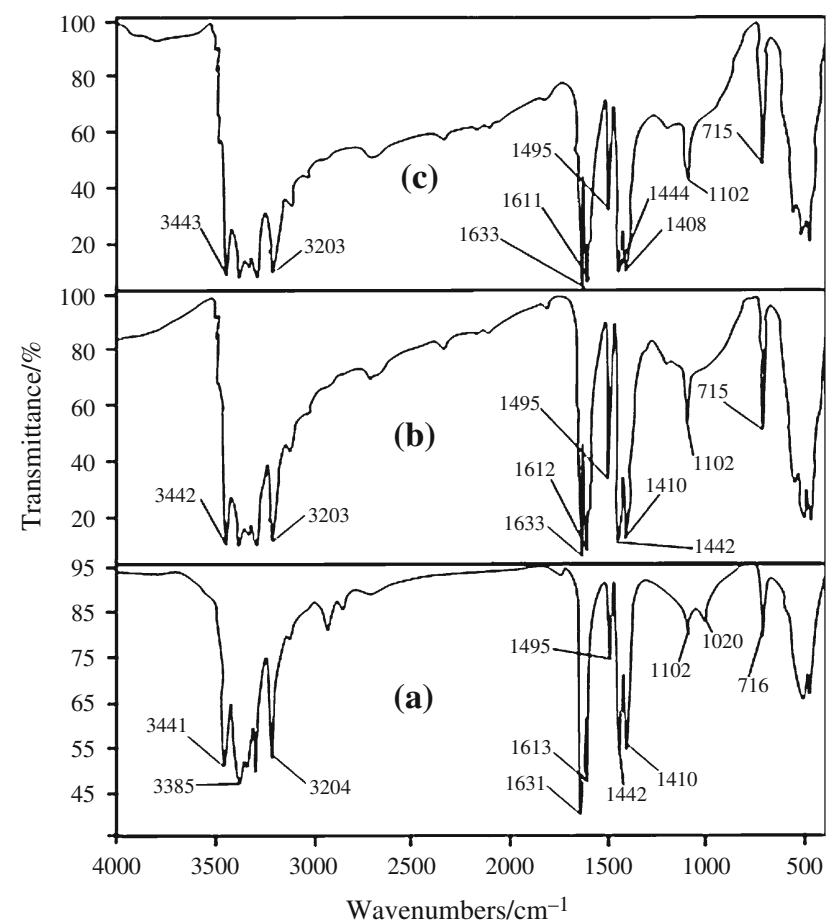

Fig. 2 FT-IR spectrum of BTZC crystals a pure b $1 \mathrm{~mol} \%$ Na-doped and $\mathbf{c} 10 \mathrm{~mol} \%$ Na-doped

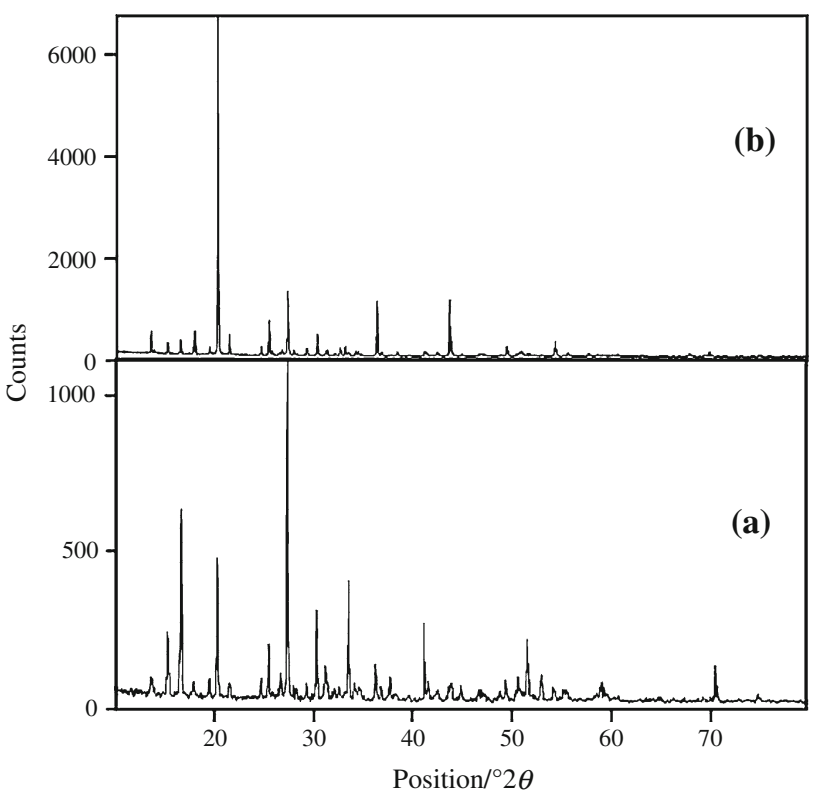

Fig. 3 Powder XRD patterns of BTZC crystals a pure and b $10 \mathrm{~mol} \% \mathrm{Na}$-doped compared with that zinc(II) $(88 \mathrm{pm})$. The crystallite sizes $(t)$ are calculated using the Scherrer equation:

$t=k \lambda / \beta \operatorname{Cos} \theta$

where $k$ is the Scherrer constant, $\lambda$ is the wavelength of $\mathrm{X}$-ray, $\theta$ is the peak position measured in radian and $\beta$ is the integral breadth of the reflections (in radian $\theta$ ) located at $2 \theta$. The crystallite size of crystalline domains which diffract coherently is increased from $\sim 24 \mathrm{~nm}$ to $\sim 38 \mathrm{~nm}$.

\section{SEM and EDS analyses}

The effect of the influence of dopants on the surface morphology of BTZC crystal faces reveals structure defect centers as seen in the SEM images (Fig. 4). SEM photographs of the doped specimen results in more scatter centers than that of the undoped specimen.

The incorporation of metals into the crystalline matrix was confirmed by EDS performed on BTZC (Fig. 5). It appears that the accommodating capability of host crystal is limited and only a small quantity is incorporated into the BTZC crystalline matrix.

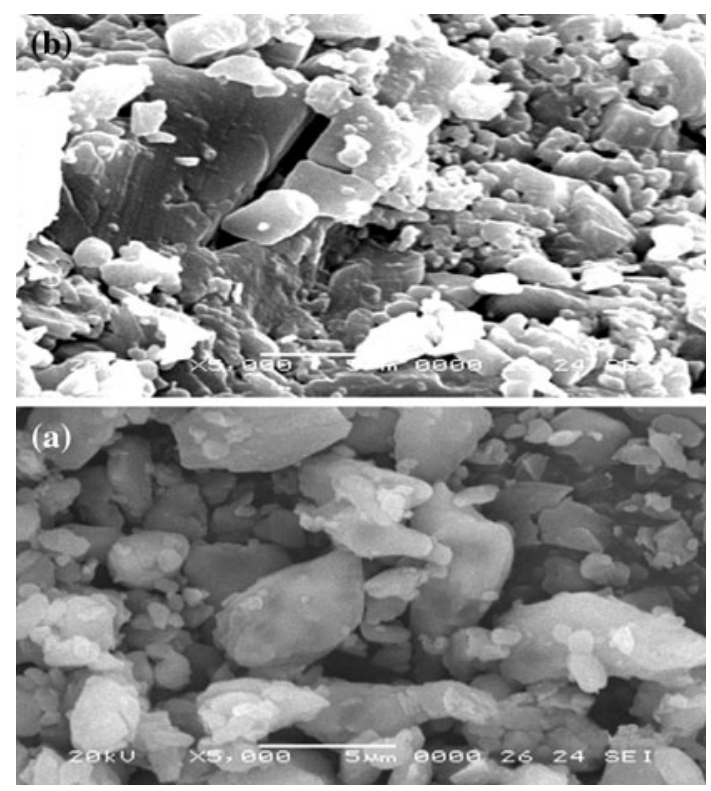

Fig. 4 SEM images of BTZC crystals a pure and b $10 \mathrm{~mol} \%$ Na-doped

Table 1 Values of lattice constants a, b, c, cell volume and crystallite size

\begin{tabular}{llllll}
\hline Crystal & $\mathrm{a} / \AA$ & $\mathrm{b} / \AA$ & $\mathrm{c} / \AA$ & Volume/ $^{3}$ & Cryst. size/nm \\
\hline Pure BTZC & 12.80 & 12.62 & 5.78 & 934 & 24.12 \\
Doped BTZC & 12.99 & 12.73 & 5.87 & 970 & 38.03 \\
\hline
\end{tabular}




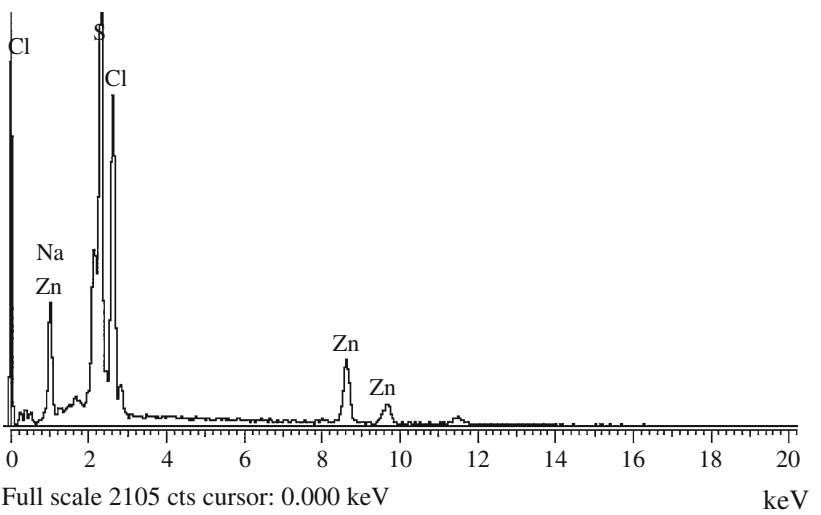

Fig. 5 EDS spectrum of 10 mol\% Na-doped BTZC
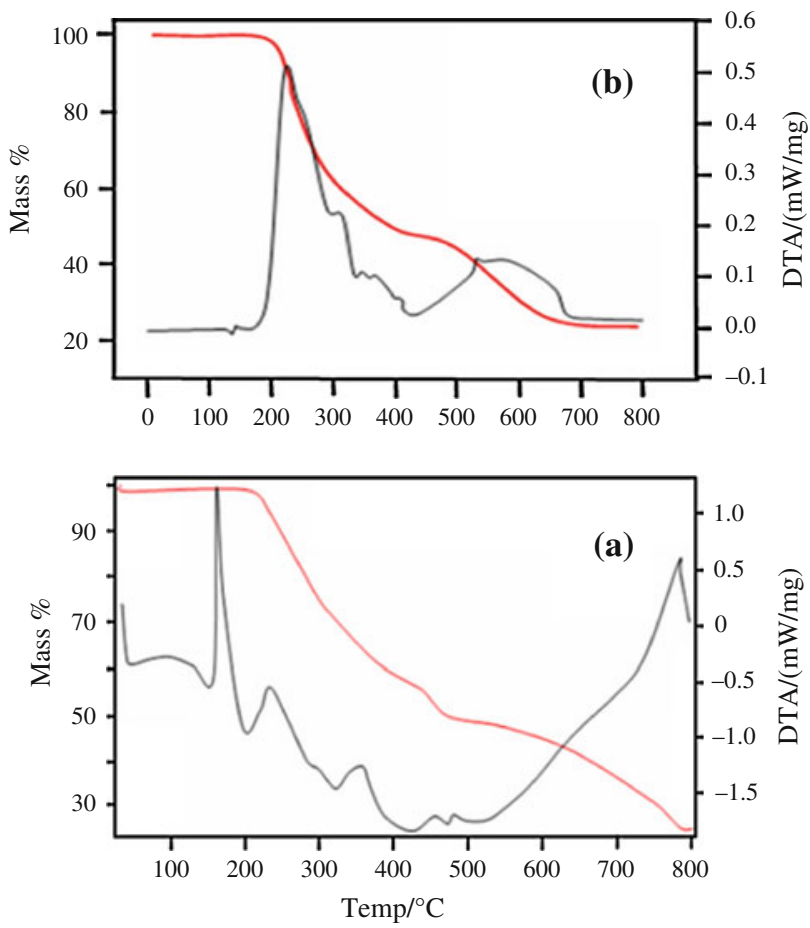

Fig. 6 TG-DTA curves of BTZC crystals a pure and b Na-doped

\section{Thermal studies}

The absence of water of crystallization in the molecular structure is indicated by the absence of mass loss around $100{ }^{\circ} \mathrm{C}$ (Fig. 6a, b). Melting point of the sample is slightly lowered in the case of $\mathrm{Na}^{+}$-added BTZC (Fig. 6b). A good thermal stability of the material is observed up to $\sim 220{ }^{\circ} \mathrm{C}$ and the thermal behaviour is not very much altered in the presence of the dopant, sodium. No decomposition up to the melting point ensures the suitability of the material for application in lasers where the crystals are required to withstand high temperatures.

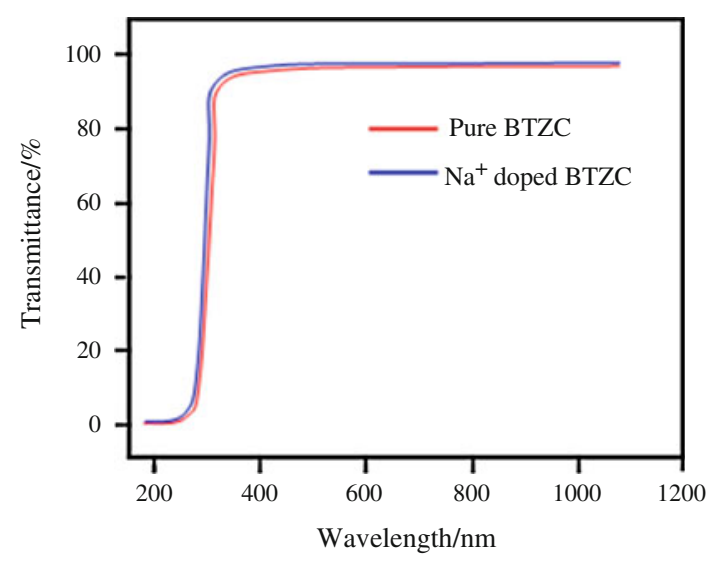

Fig. 7 UV-Vis spectra of a pure BTZC and b $10 \mathrm{~mol} \%$ Na-doped BTZC

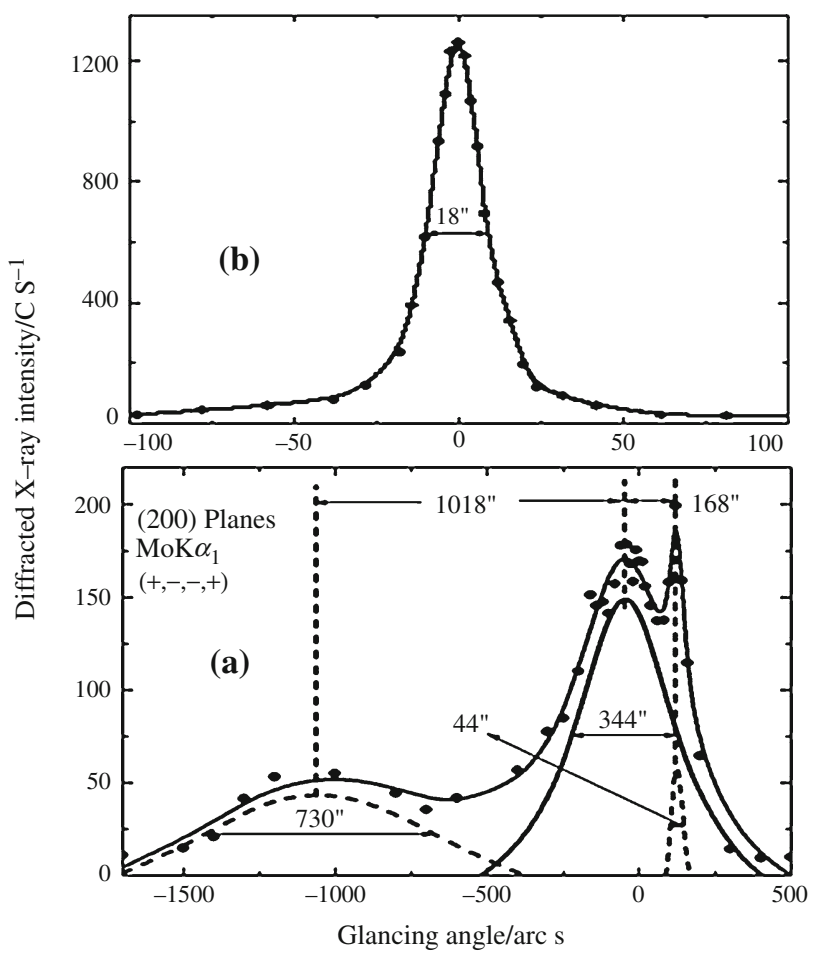

Fig. 8 HRXRD patterns recorded for a pure BTZC and b $10 \mathrm{~mol} \%$ Na-doped BTZC

\section{Optical transmission studies}

The UV spectrum reveals that the cut off wavelength is $\sim 284 \mathrm{~nm}$ (Fig. 7). Transmittance is maximum in the $300-1,100 \mathrm{~nm}$ region. It appears that the doping does not destroy the optical transmission. No significant $\lambda$ max shift is observed.

\section{$H R X R D$}

Figure 8a shows the high-resolution diffraction curve (DC) recorded for a typical BTZC single crystal specimen using 
(200) diffracting planes in symmetrical Bragg geometry. The solid line (convoluted curve) is well fitted with the experimental points represented by the filled circles. On deconvolution of the diffraction curve, it is clear that the curve contains two additional peaks, which are 1,018 and 168 arc s away from the main peak. These two additional peaks correspond to two internal structural low angle boundaries whose tilt angles are 1,018 and 168 arc s from the main crystal block. The FWHM (full width at half maximum) of the main peak and the low angle boundaries are 344 and 730 and 44 arc s, respectively. Though the specimen contains low angle boundaries, the relatively low angular spread of around 2,000 arc s (around half a degree) of the diffraction curve and the low FWHM values show that the crystalline perfection is reasonably good. The effect of such very low angle boundaries may not be very significant in many device applications, but for applications like phase matching, it is better to know these minute details regarding crystalline perfection.

Figure $8 \mathrm{~b}$ shows the high-resolution diffraction curve (DC) recorded for doped specimen using (020) diffracting planes in symmetrical Bragg geometry by employing the multicrystal X-ray diffractometer described above with $\mathrm{MoK} \alpha_{1}$ radiation. As seen in the figure the DC is quite sharp without any satellite peaks which may otherwise be observed either due to internal structural grain boundaries [45] or due to epitaxial layer which may sometimes form in crystals grown from solution [46]. The full width at half maximum (FWHM) of the diffraction curves is 18 arc sec, which is very close to that expected from the plane wave theory of dynamical $\mathrm{X}$-ray diffraction [47]. The single sharp diffraction curve with very low FWHM indicates that the crystalline perfection is extremely good. The specimen is a nearly perfect single crystal without having any internal structural grain boundaries.

\section{Conclusions}

The influence of sodium-doping on the BTZC crystal has been studied. A close observation of XRD and FT-IR profiles of doped and undoped specimens reveals some minor structural variations. These studies indicate that the crystal undergoes considerable lattice stress as a result of doping. Energy dispersive spectrum reveals the incorporation of $\mathrm{Na}(\mathrm{I})$ in the crystalline matrix of BTZC crystals. SEM images reveal that the external morphology of BTZC crystal is changed by doping. The thermal stability of the material is not altered much by doping. UV-Visible study shows that the transparency is slightly affected by the dopant.

\section{References}

1. Velsko S. Laser program annual report, Lawrence UCRL-JC 105000. Livermore CA: Lawrence Livemore National Laboratory; 1990.

2. Guangcai X, Minhua M, Zongshu Z, Xu D. Bis-thiourea cadmium chloride(BTCC) - a novel organic crystal of organometallic complex. Chin J Lasers. 1987;14:357-63.

3. Marcy HO, Warren LF, Webb MS, Ebbers CA, Velsko SP, Kennedy GC, Caterlla GC. Second-harmonic generation in zinc tris(thiourea)sulfate. Appl Opt. 1992;31:5051-60.

4. Angeli Mary PA, Dhanuskodi S. Growth and characterization of a new nonlinear optical crystal: bis thiourea zinc chloride. Cryst Res Technol. 2001;36:1231-7.

5. Long X, Wang G, Han TPJ. Growth and spectroscopic properties of $\mathrm{Cr}^{3+}$-doped $\mathrm{LaSc}_{3}\left(\mathrm{BO}_{3}\right)_{4}$. J Cryst Growth. 2003;249:191-4.

6. Ramajothi J, Dhanuskodi S. Optical and microhardness studies of semi organic nonlinear optical material: L-histidine tetrafluoroborate. Cryst Res Technol. 2003;38:986-91.

7. Ohachi T, Hamanada M, Konda H, Hayashi D, Taniguchi I, Hashimoto $\mathrm{T}$, Kotani $\mathrm{Y}$. Electrical nucleation and growth of $\mathrm{NaCH}_{3} \mathrm{COO} 3 \mathrm{H}_{2} \mathrm{O}$. J Cryst Growth. 1990;99:72-6.

8. Wang XQ, Xu D, Lu MK, Yuan DR, Huang J, Li SG, Lu GW, Sun HQ, Guo SY, Zhang GH, Duan XL, Liu HY, Liu WL. Physicochemical behavior of nonlinear optical crystal $\mathrm{CdHg}(\mathrm{SCN})_{4}$. J Cryst Growth. 2003;247:432-7.

9. Uthrakumar R, Vesta C, Justin Raj C, Dinakaran S, Christhu Dhas R, Jerome Das S. Optical and dielectric studies on pure and $\mathrm{Ni}^{2+}, \mathrm{Co}^{2+}$ doped single crystals of bis thiourea cadmium chloride. Cryst Res Technol. 2008;43:428-32.

10. Selvakumar S, Rajarajan K, Ravi Kumar SM, Ambujam K, Prem Anand D, Vetha Potheher I, Sagayaraj P. Growth and characterization of pure and metal doped bis(thiourea) zinc chloride single crystals. Cryst Res Technol. 2006;41:766-70.

11. Moitra S, Kar T. Synthesis and characterization of bis(thiourea)zinc chloride doped with L-arginine. Mater Chem Phys. 2009;117:204-8.

12. Balu T, Rajasekaran TR, Murugakoothan P. Nucleation studies of ZTC doped with L-arginine in supersaturated aqueous solutions. Phys B. 2009;404:813-1818.

13. Dhumane NR, Hussaini SS, Dongre VG, Ghugare P, Shirsat MD. Growth and characterization of L-alanine-doped zinc thiourea chloride single crystal (ZTC). Appl Phys A. 2009;95:727-32.

14. Rajasekaran R, Rajendiran KV, Mohan Kumar R, Jayavel R, Dhanasekaran R, Ramasamy P. Investigation on the nucleation kinetics of zinc thiourea chloride (ZTC) single crystals. Mater Chem Phys. 2003;82:273-80.

15. Rajasekaran R, Rajasekaran R, Ushashree PM, Ramasamy P. Growth and characterization of zinc thiourea chloride (ZTC): a semi organic nonlinear optical crystal. J Cryst Growth. 2001;229:563-7.

16. Moitra S, Kar T. Growth, optical and thermal characterization of bis(thiourea)zinc chloride single crystals. Opt Mater. 2008;30: 1621-4.

17. Rajasekaran R, Mohankumar R, Jeyavel R, Ramasamy P. Influence of $\mathrm{pH}$ on the growth and characteristics of nonlinear optical zinc thiourea chloride (ZTC) single crystals. J Cryst Growth. 2003;252:317-27.

18. Rajasekaran R, Rajendiran KV, Mohan Kumar R, Jayavel R, Dhanasekaran R, Ramasamy P. Investigation on the nucleation kinetics of zinc thiourea chloride (ZTC) single crystals. Mater Chem Phys. 2003;82:273-80.

19. Kushwaha SK, Vijayan N, Bhagavannarayana G. Growth by SR method and characterization of bis(thiourea)zinc(II) chloride single crystals. Mater Lett. 2008;62:3931-3. 
20. Uthrakumar R, Vesta C, Justin Raj C, Krishnan S, Jerome Das S. Bulk crystal growth and characterization of non-linear optical bisthiourea zinc chloride single crystal by unidirectional growth method. Curr Appl Phys. 2010;10:548-52.

21. Lal K, Bhagavannarayan G. A high-resolution diffuse X-ray scattering study of defects in dislocation-free silicon crystals growth by the float-zone method and comparison with Czochralski-grown crystals. J Appl Cryst. 1989;22:209-15.

22. Meenakshisundaram S, Parthiban S, Sarathi N, Kalavathy R, Bhagavannarayana G. Effect of organic dopants on ZTS single crystals. J Cryst Growth. 2006;293:376-81.

23. Kuznetsov VA, Okhrimenko TM, Rak M. Growth promoting effect of organic impurities on growth kinetics of KAP and KDP crystals. J Cryst Growth. 1998;193:164-73.

24. Bhagavannarayana G, Ananthamurthy RV, Budakoti GC, Kumar B, Bartwal KS. A study of the effect of annealing on Fe-doped $\mathrm{LiNbO}_{3}$ by HRXRD, XRT and FT-IR. J Appl Cryst. 2005;38: 768-71.

25. Bhagavannarayana G, Parthiban S, Meenakshisundaram S. Enhancement of crystalline perfection by organic dopants in ZTS, ADP and KHP crystals as investigated by high-resolution XRD and SEM. J Appl Cryst. 2006;39:784-90.

26. Batterman BW, Cole H. Dynamical diffraction of X-rays by perfect crystals. Rev Mod Phys. 1964;36:681-717.

27. Mojumdar SC, Raki L. Preparation, thermal, spectral and microscopic studies of calcium silicate hydrate-poly(acrylic acid) nanocomposite materials. J Therm Anal Calorim. 2006;85: 99-105.

28. Sawant SY, Verenkar VMS, Mojumdar SC. Preparation, thermal, $\mathrm{XRD}$, chemical and FT-IR spectral analysis of $\mathrm{NiMn}_{2} \mathrm{O}_{4}$ nanoparticles and respective precursor. J Therm Anal Calorim. 2007; 90:669-72.

29. Porob RA, Khan SZ, Mojumdar SC, Verenkar VMS. Synthesis, TG, SDC and infrared spectral study of $\mathrm{NiMn}_{2}\left(\mathrm{C}_{4} \mathrm{H}_{4} \mathrm{O}_{4}\right)_{3}$. $6 \mathrm{~N}_{2} \mathrm{H}_{4}$-a precursor for $\mathrm{NiMn}_{2} \mathrm{O}_{4}$ nanoparticles. J Therm Anal Calorim. 2006;86:605-8.

30. Mojumdar SC, Varshney KG, Agrawal A. Hybrid fibrous ion exchange materials: past, present and future. Res J Chem Environ. 2006;10:89-103.

31. Doval M, Palou M, Mojumdar SC. Hydration behaviour of $\mathrm{C}_{2} \mathrm{~S}$ and $\mathrm{C}_{2} \mathrm{AS}$ nanomaterials, synthesized by sol-gel method. J Therm Anal Calorim. 2006;86:595-9.

32. Mojumdar SC, Moresoli C, Simon LC, Legge RL. Edible wheat gluten (WG) protein films: preparation, thermal, mechanical and Spectral Properties. J Therm Anal Calorim. 2011;104:929-36.

33. Varshney G, Agrawal A, Mojumdar SC. Pyridine based cerium(IV) phosphate hybrid fibrous ion exchanger: Synthesis, characterization and thermal behaviour. J Therm Anal Calorim. 2007;90:731-4.
34. Mojumdar SC, Melnik M, Jona E. Thermal and spectral properties of $\mathrm{Mg}(\mathrm{II})$ and $\mathrm{Cu}(\mathrm{II})$ complexes with heterocyclic N-donor ligands. J Anal Appl Pyrolysis. 2000;53:149-60.

35. Borah B, Wood JL. Complex hydrogen bonded cations. The benzimidazole benzimidazolium cation. Can J Chem. 1976;50: 2470-81.

36. Mojumdar SC, Sain M, Prasad RC, Sun L, Venart JES. Selected thermoanalytical methods and their applications from medicine to construction. J Therm Anal Calorim. 2007;60:653-62.

37. Meenakshisundarm SP, Parthiban S, Madhurambal G, Mojumdar SC. Effect of chelating agent (1,10-phenanthroline) on potassium hydrogen phthalate crystals. J Therm Anal Calorim. 2008;94: 21-5.

38. Rejitha KS, Mathew S. Investigations on the thermal behavior of hexaamminenickel(II) sulphate using TG-MS and TR-XRD. Glob J Anal Chem. 2010;1(1):100-8.

39. Pajtášová M, Ondrušová D, Jóna E, Mojumdar SC, Ľalíková S, Bazyláková T, Gregor M. Spectral and thermal characteristics of copper(II) carboxylates with fatty acid chains and their benzothiazole adducts. J Therm Anal Calorim. 2010;100:769-77.

40. Madhurambal G, Ramasamy P, Anbusrinivasan P, Vasudevan G, Kavitha S, Mojumdar SC. Growth and characterization studies of 2-bromo-4'-chloro-acetophenone (BCAP) crystals. J Therm Anal Calorim. 2008;94:59-62.

41. Gonsalves LR, Mojumdar SC, Verenkar VMS. Synthesis and characterisation of $\mathrm{Co}_{0.8} \mathrm{Zn}_{0.2} \mathrm{Fe}_{2} \mathrm{O}_{4}$ nanoparticles. J Therm Anal Calorim. 2011;104:869-73.

42. Raileanu M, Todan L, Crisan M, Braileanu A, Rusu A, Bradu C, Carpov A, Zaharescu M. Sol-gel materials with pesticide delivery properties. J Environ Prot. 2010;1:302-13.

43. Varshney KG, Agrawal A, Mojumdar SC. Pectin-based cerium(IV) and thorium(IV) phosphates as novel hybrid fibrous ion exchangers synthesis, characterization and thermal behaviour. J Therm Anal Calorim. 2005;81:183-9.

44. Mojumdar SC, Šimon P, Krutošíková A. [1]Benzofuro[3,2c]pyridine: synthesis and coordination reactions. J Therm Anal Calorim. 2009;96:103-9.

45. Moricová K, Jóna E, Plško A, Mojumdar SC. Thermal stability of $\mathrm{Li}_{2} \mathrm{O}-\mathrm{SiO}_{2}-\mathrm{TiO}_{2}$ gels evaluated by the induction period of crystallization. J Therm Anal Calorim. 2010;100:817-20.

46. Mojumdar SC, Miklovic J, Krutosikova A, Valigura D, Stewart JM. Furopyridines and furopyridine-Ni(II) complexes-synthesis, thermal and spectral characterization. J Therm Anal Calorim. 2005;81:211-5.

47. Vasudevan G, AnbuSrinivasan P, Madhurambal G, Mojumdar SC. Thermal analysis, effect of dopants, spectral characterisation and growth aspects of KAP crystals. J Therm Anal Calorim. 2009;96:99-102. 